Letter

\title{
Utilizing Hyperspectral Remote Sensing for Soil Gradation
}

\author{
Jordan Ewing ${ }^{1}$, Thomas Oommen ${ }^{2, *(\mathbb{D}}$, Paramsothy Jayakumar ${ }^{3}$ and Russell Alger 4 \\ 1 Department of Computational Science and Engineering, Michigan Technological University, \\ Houghton, MI 49931, USA; jjewing@mtu.edu \\ 2 Department of Geological and Mining Engineering and Sciences, Michigan Technological University, \\ Houghton, MI 49931, USA \\ 3 U.S. Army CCDC Ground Vehicle Systems Center, Warren, MI 48092, USA; \\ paramsothy.jayakumar.civ@mail.mil \\ 4 The Institute of Snow Research, Keweenaw Research Center, Calumet, MI 49913, USA; rgalger@mtu.edu \\ * Correspondence: toommen@mtu.edu
}

Received: 19 September 2020; Accepted: 9 October 2020; Published: 12 October 2020

check for updates

\begin{abstract}
Soil gradation is an important characteristic for soil mechanics. Traditionally soil gradation is performed by sieve analysis using a sample from the field. In this research, we are interested in the application of hyperspectral remote sensing to characterize soil gradation. The specific objective of this work is to explore the application of hyperspectral remote sensing to be used as an alternative to traditional soil gradation estimation. The advantage of such an approach is that it would provide the soil gradation without having to obtain a field sample. This work will examine five different soil types from the Keweenaw Research Center within a laboratory-controlled environment for testing. Our study demonstrates a correlation between hyperspectral data, the percent gravel and sand composition of the soil. Using this correlation, one can predict the percent gravel and sand within a soil and, in turn, calculate the remaining percent of fine particles. This information can be vital to help identify the soil type, soil strength, permeability/hydraulic conductivity, and other properties that are correlated to the gradation of the soil.
\end{abstract}

Keywords: soil mechanics; spectral analysis; soil classification index; USCS; terramechanics

\section{Introduction}

The gradation (grain size distribution) is an important characteristic that influences the physical and mechanical properties of the soil. Studies show that the gradation of soils carries important details of the soil's mechanical properties and that one can create an index to find correlations to these values [1]. Kuenza [2] has looked into gravel and sand composition of soils in mountainous areas with slope instability; based on the amount of sand versus the amount of gravel present it was determined which particle size has a more dominating influence over the soil's stress-strain behavior for an undrained torsional shear test. The percentage of gravel and sand content in soil influences the shear strength and dilatancy of sand-gravel mixtures. Therefore, knowing the gradation of the soil can help estimate the soil's properties [3]. While gradation is a useful metric for geotechnical engineering, its estimation requires an in situ sample collection. Presently, soil gradation is primarily done via sieve analysis (also called a gradation test). The traditional approach of in situ sample collection and sieve analysis can be laborious, costly, and challenging to attain in remote or unfriendly territories. Therefore, ways to remotely characterize soil gradation can be of significant benefit for many applications.

One such application is in the mobility of military vehicles in unknown territories. There is present work being done where terrain strength characteristics and land mapping for autonomous mobility 
and simulation modeling are quintessential. The methods for the past models have relied heavily on in situ measurements, which requires one to gather the soil from an area of interest, which can be hard to obtain or impossible in war-zones and remote territories, and they are looking to be improved [4]. Therefore, we present an alternative method for predicting the gradation of the soil using remote sensing that would be particularly beneficial for remote territories.

With the rapid increase of computational capabilities and sensor improvements, remote sensing has developed into a more time-efficient and accurate tool, which will continue to grow with new and emerging ideas [5-9]. Remote imagery provides a means of quick and efficient data collection for rapid assessment of an area. Previous work has been done on analyzing the use of different means via cameras, unmanned aerial vehicles (UAVs), and satellites to provide a way to measure sand lower bound friction angles and bearing strength [10]. The agricultural industry has recently utilized techniques such as laser-induced breakdown spectroscopy (LIBS) for quantifying nutrients within soil [11]. Other techniques, such as X-ray diffraction [12-14] and diffuse reflectance spectroscopy [15] have been used for soil mineral classification. These methods are limited as they are either destructive (LIBS) or costly/time consuming (X-ray diffraction). Hyperspectral remote sensing is both a nondestructive and time efficient testing method. Hyperspectral imaging has already worked towards predicting heavy metal soil contamination [16], improving our ability to do anomaly detection, target recognition, and mineral characterization [17]. Studies using both multispectral and hyperspectral sensors show promise in the use of optical remote sensing to provide a novel method for improving the mapping of soils for discriminating between variational levels of sand and clay content [18]. Using hyperspectral data, one can predict different features/characteristics of bare soil, and certain wavelengths may provide a means of identifying/distinguishing certain features [19,20]. The agriculture field has utilized soil spectral reflectance for many purposes, such as identifying reflectance effects based on moisture content, soil tilling, organic material, iron content, and minerals within the soil [21-28] and how the open soil surface patterns impact that reflectance [29]. Visible and near-infrared spectroscopy has already been used for identifying clay mineral contents within the soil [30], and shown ease of use and good agreement with identifying soil mineral composition to that of X-ray diffraction analysis [31]. In contrast, this study focuses on characterizing the soil from a soil mechanics perspective.

Hyperspectral remote sensing has the capability of determining attributes such as clay and sand content of soil within the laboratory and field. This could be especially useful when a large number of soil analysis needs to be done and may provide a real-time method for field data collection [32]. Expanding beyond this, studies have already shown promise in developing a soil index, to help improve the classification of different colored sands based on both color and curvature of reflectance spectrums. However, work still needs to be done for differing water conditions, grain size distribution, and other factors [33]. Currently, there is research being done on the best algorithms to implement for processing hyperspectral data to classify different land cover types better. Considerable success has already been found using support vector machine (SVM) methods for classifying hyperspectral data over multiple land cover types [34]. Hyperspectral imaging of topsoil with the use of regression modeling has proved to be able to predict sand and clay percentages in a bare field [35]. Hyperspectral remote sensing shows promise as a rapid and non-destructive means to measure the soil gradation. In this study, we propose the use of hyperspectral remote sensing utilizing the visible and near-infrared (NIR) range (400-1000 nm) as this range of wavelengths is more readily available and will deliver a cost-effective solution for field implementation. In our paper, we verify the applicability of hyperspectral remote sensing to characterize the gradation of five different soil types.

\section{Materials and Methods}

In this study, we analyzed five different soil types obtained from the Keweenaw Research Center (KRC) that are used for testing different terramechanics properties. These soils are labeled as Fine, Coarse, Rink, Stability, and 2NS, which have varying amounts of sand, gravel, and fine particles. 
The soils we examined are coarse-grained or fine-grained and have no clay or organic content. Lab analysis of the soils was done prior to testing to calculate the soil parameters such as D10, D30, and D60 (the grain size at 10\%, 30\%, and 60\% of the sample passing through a specific sieve size), coefficient of uniformity $(\mathrm{Cu})$ and coefficient of curvature $(\mathrm{Cc})$ shown in Equations (1) and (2) respectively, Unified Soil Classification for Soil (USCS) [36], and confirm there were no clays or organics present. The specifics for these soils are listed in Table 1 . The locations of these soils at KRC are shown in Figure 1.

$$
\begin{gathered}
\mathrm{Cu}=\mathrm{D} 60 / \mathrm{D} 10, \\
\mathrm{Cc}_{\mathrm{C}}=(\mathrm{D} 30)^{\wedge} 2 /(\mathrm{D} 10 \times \mathrm{D} 60),
\end{gathered}
$$

Table 1. Keweenaw Research Center (KRC) Soil Information. \% Gravel, \% Sand, \% Fine, D10, D30, D60, Cu, Cc, and Unified Soil Classification for Soil (USCS) Classification.

\begin{tabular}{cccccc}
\hline & Fine & Coarse & Rink & Stability & 2NS \\
\hline \% Gravel & 0.0 & 16.8073 & 10.7 & 31.1 & 0.6 \\
\% Sand & 40.6 & 73.73772 & 66.4 & 58.8 & 97.3 \\
\% Fine & 59.4 & 9.454973 & 23.0 & 10.0 & 2.1 \\
D10 & 0.0151 & 0.085 & 0.015 & 0.075 & 0.175 \\
D30 & 0.043 & 0.27 & 0.12 & 0.25 & 0.315 \\
D60 & 0.076 & 0.38 & 16.7 & 35.3 & 0.7 \\
Cu & 5.03 & 4.5 & 3.8 & 0.3 & 0.7 \\
Cc & 1.61 & 2.3 & SW-SM = Well & SP = Poorly \\
USCS & ML $=$ Sandy Silt & Graded Sand with & SM = Silty Sand & Graded Sand with & Graded Sand \\
Classification & & Silt and Gravel & Silt and Gravel & \\
\hline
\end{tabular}
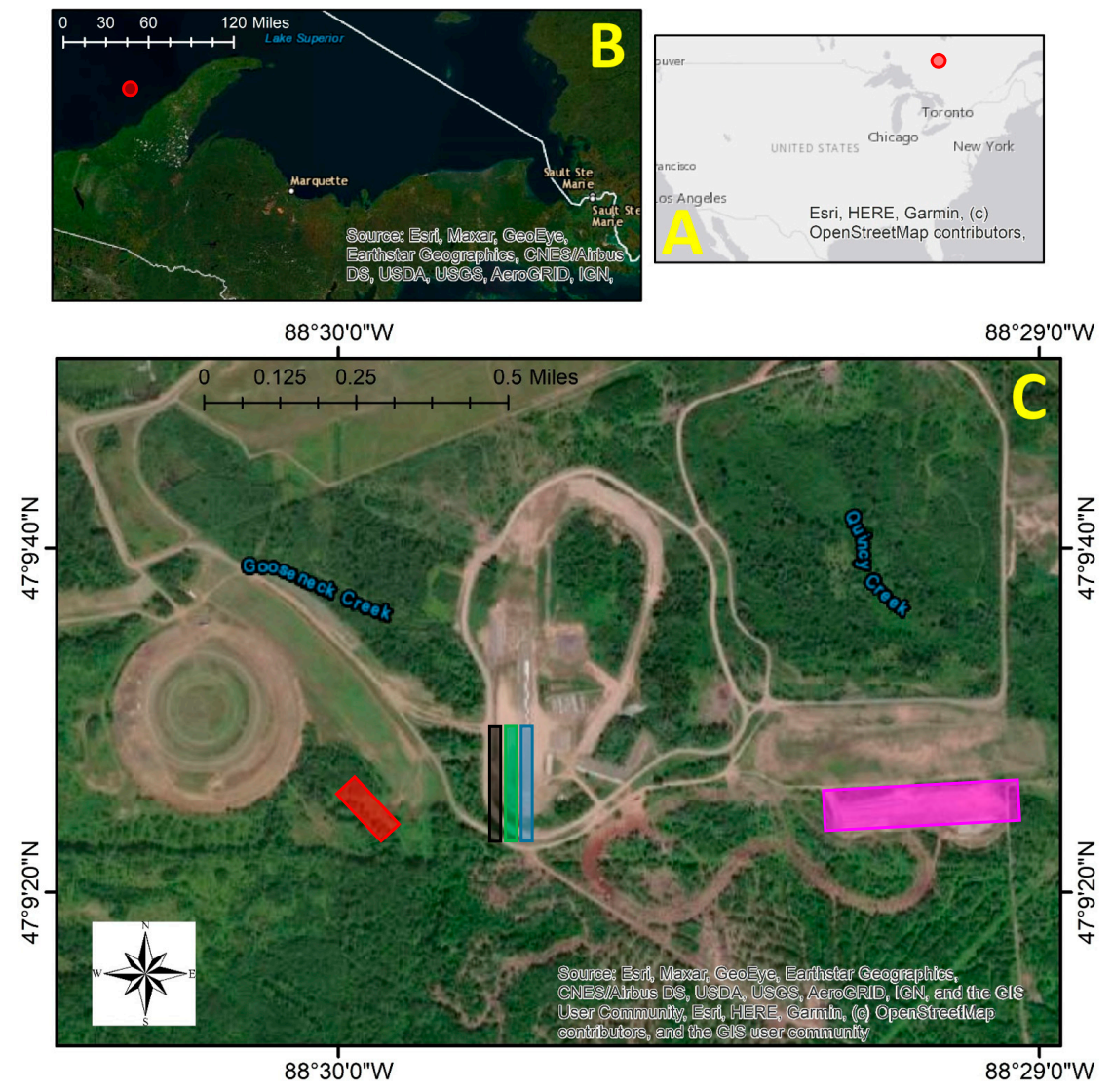

Figure 1. (A) Map of USA, (B) Location of KRC in Upper Peninsula of Michigan, (C) and the location of the five soil pits at KRC highlighted. Boxes show area of the soil pits: Fine (red), Coarse (blue), Rink (green), Stability (purple), and 2NS (black). 
The study was conducted in the lab, with each of the five soils placed into their bin with dimensions roughly $61 \mathrm{~cm} \times 61 \mathrm{~cm} \times 30.5 \mathrm{~cm}$ (Length $\times$ Width $\times$ Height). These were then set in a row under a series of work lights ( $1 \mathrm{~m}$ above soil surface) and a track to have the hyperspectral camera move over the soils in a straight and level manner, as shown in Figure 2. These work lights provide, similar to all incandescent light bulbs, a continuous spectrum of wavelengths from the near ultraviolet to the far infrared region.

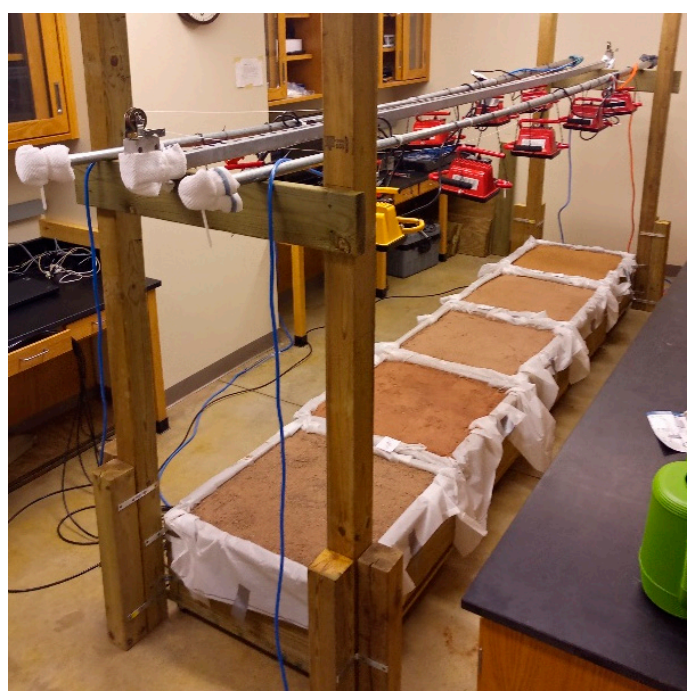

Figure 2. Shows the lab setup of the $5 \mathrm{KRC}$ soils. The soils in order from bottom left to top right: 2NS, Stability, Rink, Coarse, and Fine. Above each bin are two 500-Watt work lights whose field of view cover the entire soil bin, and the middle bar is the track; the hyperspectral camera is moved along.

\subsection{Remote Sensing Background}

Most everyday cameras operate within three bands, red, green, and blue. These cameras provide us the color images we see in a regular photograph. However, there are many bands in the electromagnetic (EM) spectrum to which certain cameras can distinguish. If the light were to reflect from a smooth white surface, one would receive a $100 \%$ reflectance since nothing is absorbed into the material. Most objects have color, roughness, texture, which all change the amount of light reflected to the camera. The reflectance values for each different wavelength is then recorded by the camera, which is then processed and analyzed to produce a multitude of information. Hyperspectral and multispectral cameras work by taking this reflected EM energy from the surface and record the response.

\subsection{Sensors and Hardware}

In this study, different spectral resolution hyperspectral sensors were used: a BaySpec OCI-F hyperspectral camera and a very high-resolution Analytical Spectral Devices, Inc. (ASD) Spectroradiometer. This was done as a way of checking if more economically affordable hyperspectral sensors with a slightly lower spectral resolution could also be used to detect the similar features that the ASD Spectroradiometer identified. This BaySpec camera (shown in Figure 3) has a range of 400-1000 nm covering the entire visible (VIS) spectrum and some of the near infrared (NIR) region with roughly 5-7 nm full width at half $\max (\mathrm{FWHM})$ spectral resolution and 120 different bands. Only the 450-1000 $\mathrm{nm}$ range was used, as the initial 400-449 $\mathrm{nm}$ had excessive noise rendering it useless. This is also typically a very low spectral reflectance range with little variations in initial values for soils, making this range very inefficient for differentiation between soils. It is a push-broom camera, meaning it collects images as it moves in a straight line. The width of the scan line is known as the swath width. Taking images at rates of up to 60 frames per second (fps), it also has a spatial resolution of 800 pixels (swath width) by the scan-length. The camera is factory calibrated (calibration fixed permanently). 
It is equipped with a $16 \mathrm{~mm}\left(21^{\circ} \mathrm{FOV}\right)$ lens. The full technical aspects of this camera are listed in the BaySpec manual [37].

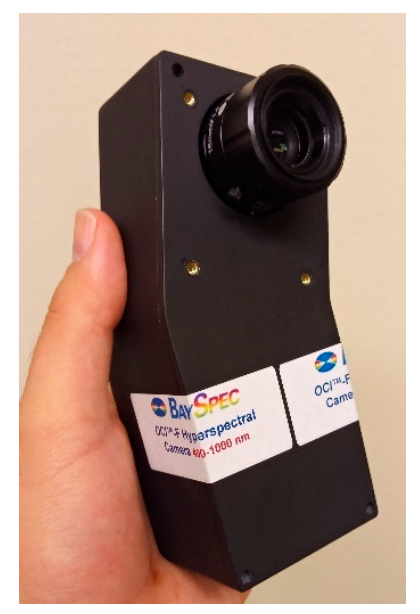

Figure 3. Shows the BaySpec hyperspectral camera used for recording these values. The range of the camera is from 400 to $1000 \mathrm{~nm}$.

A high-resolution ASD Spectroradiometer was also used, which has a useable band range from 400 to $2500 \mathrm{~nm}$. The range from 350 to $399 \mathrm{~nm}$ has a lot of noise, which makes the data unusable [38]. The device has a total of 512 bands in the VIS-NIR range (350-1000 nm), roughly 600 bands in the short wave infrared (SWIR) 1 range (1000-1830 nm), and similarly in the SWIR 2 range (1830-2500 nm). The spectral resolution is $3 \mathrm{~nm}$ (FWHM) at $700 \mathrm{~nm}, 10 \mathrm{~nm}$ (FWHM) at $1400 \mathrm{~nm}$, and $10 \mathrm{~nm}$ (FWHM) at $2100 \mathrm{~nm}$. Square spatial pixels are $1.4 \mathrm{~nm}$ for 350-1000 nm and $2 \mathrm{~nm}$ for 1000-25000 nm. The fiber optic cable is run from the device into a pistol grip, and then a (1 degree) scope was attached to the grip. The device was facing at nadir to the soil, during data collection, at the same location as the BaySpec camera at the center of each bin. The reflectance values of the region being scanned are collected in CSV format. Full technical aspects of the ASD Spectroradiometer are listed in the manual [39].

To collect the volumetric water content, a CR1000X is used with the CS615 probes. The CS615 water content reflectometer is connected to the CR1000X datalogger which is used to collect the measured volumetric water content. This is measured through the effect of a changing dielectric constant on the EM waves propagating along a waveguide. This method is called time domain reflectometry. The technical details of the CR1000X and CS615 are available from the manuals [40,41]. The CS615 water content probes are set to record the water content average over a 15-min interval. The probes being $30.5 \mathrm{~cm}$ in length are placed into the soil at around an angle to be fully submerged into the soil and reach the bottom of the bin.

\subsection{Laboratory Testing Methodology}

First, the volumetric water content probes were inserted into the bins, and the water content was collected for $15 \mathrm{~min}$. The average moisture content was then recorded for each of the soil bins. After the time allotted, the probes were removed, and the work lights were turned on. The BaySpec camera was loaded onto a trolley, which was then moved at nadir across all five bins. Once images were collected, the BaySpec CubeCreator automatically combines all the individual slices and stitches them into one wide image. This is then used to highlight each individual bin and see the average reflectance curve over that area of interest. Each wavelength recorded will have its own specific/unique value. For example, red reflectance at $700 \mathrm{~nm}$ wavelength could be $20 \%, 0.2$, while blue reflectance at $500 \mathrm{~nm}$ wavelength is $30 \%, 0.3$. Figure 4 shows the soil bins (color image), the area captured by the camera (greyscale), and the hyperspectral plot after the software averages the pixel values for one of the trials done with the 
BaySpec camera. The BaySpec camera tested the soils at varying water contents ranging from 2 to $5 \%$ moisture content, with the Stability soil having one trial with $8 \%$.

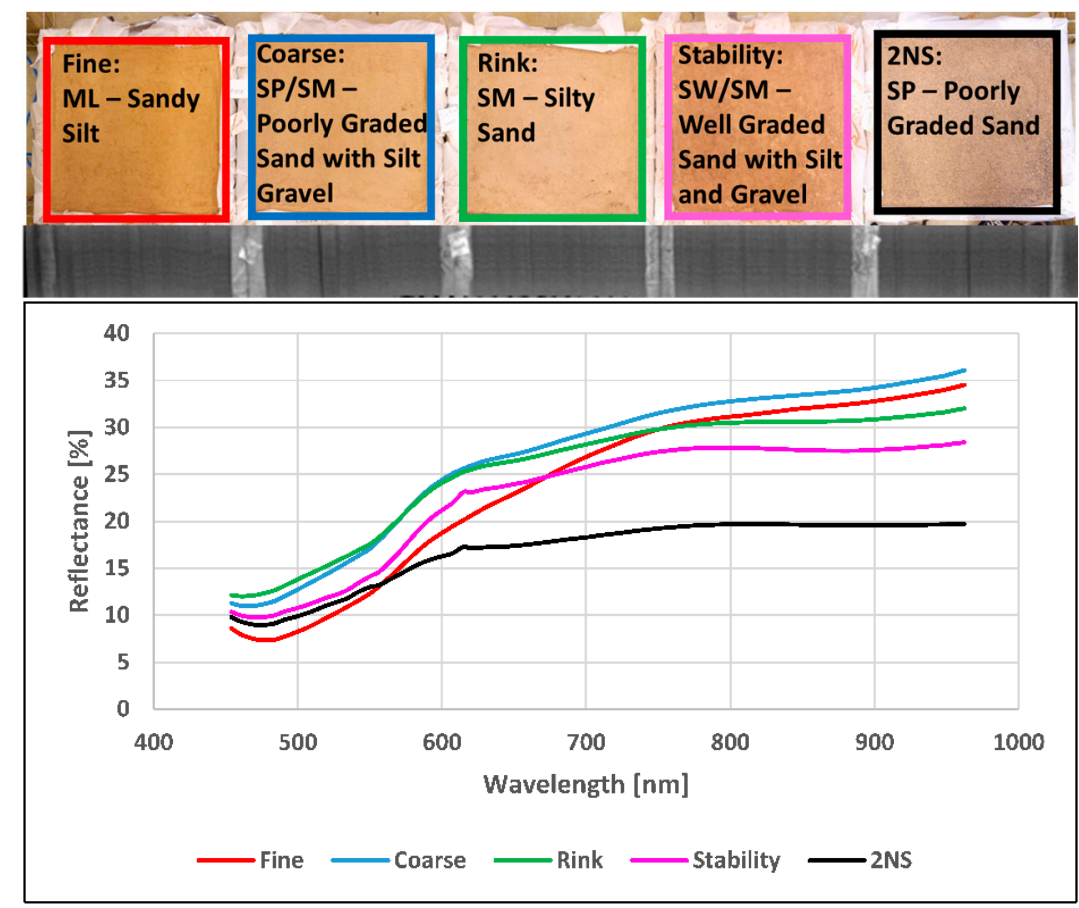

Figure 4. Shows the hyperspectral plot for each soil. Each colored box and the corresponding line is a different soil type. Going from left to right: Fine, Coarse, Rink, Stability, and 2NS.

The ASD Spectroradiometer is then placed with the optical gun facing directly down at nadir to the soil in the center. It was placed in such a manner that there were no shadows being cast onto the soil. A series of 10 consecutive tests were done over this area and then averaged to get the final reflectance for each soil type.

Once all the soils had been recorded on both devices, the lights were shut off, and water was poured onto the soils via a watering can to simulate rainfall. The BaySpec camera was not used after the first test due to the processing time of the images collected, so it will only be examining drier conditions. Different moisture content levels were tested, ranging from 2 to $<15 \%$ by adding various amounts of water in between trials and allowing around 10-15 min for the water to be absorbed by the soil to see if the moisture content influenced the results. Then the process was repeated using only the ASD Spectroradiometer to collect this data. The soil images and values from both sensors are then processed, and reflectance curves are gathered for each soil bin.

\section{Results}

Based on these hyperspectral curves, a novel soil classification index was developed for each soil, Equation (3). The developed index provides a means to identify the percent sand and gravel within a soil using hyperspectral remote sensing and leaving the remaining amount of soil to be comprised of fine particles. Needing only the reflectance values at 550,600, and $650 \mathrm{~nm}$ range of a hyperspectral image, the range is within the visible spectrum (Figure 5). These values we feel are representative of roughly the first 10-15 cm of the soil as the exposed surface is the topsoil which should have approximately the same gradation in this range. The index did not vary much with water being added, in other words increasing the moisture content of the soil, as this is a normalized value and is concerned with the slope of the reflectance curve, not the exact reflectance values. After completing multiple trials, these bands provided max spectral variance among the classes (gravel, sand, and fine). A more extensive search 
using machine learning will be carried out in the future. The index was checked at different moisture contents by adding water to the soil ranging from 0 to $4000 \mathrm{~mL}$, see Figure 6.

Soil Classification Index $=(\mathrm{R} 650-\mathrm{R} 550) / \mathrm{R} 600$,

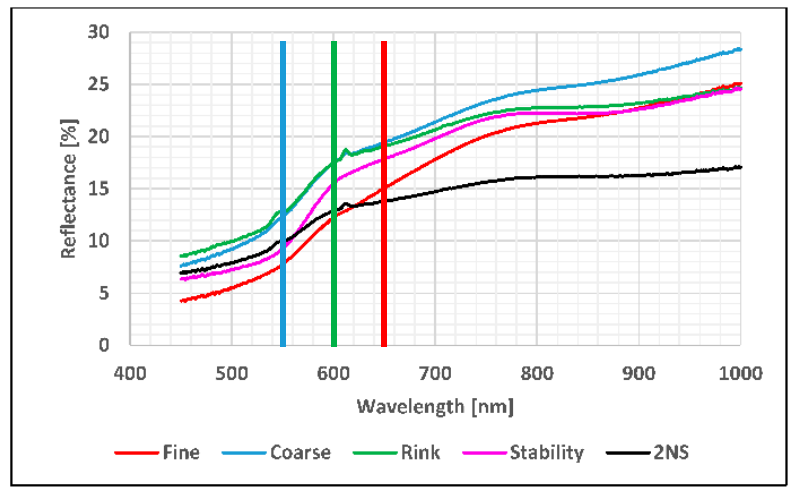

Figure 5. Shows the averaged Analytical Spectral Devices (ASD) Spectroradiometer hyperspectral plot for each soil and the location of the needed values for the soil classification index within the range of the BaySpec camera (450-1000 nm).

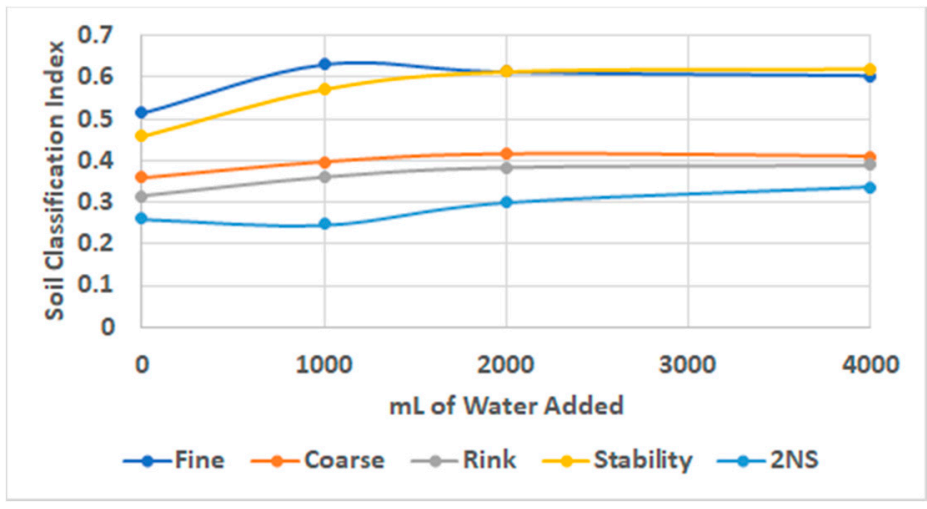

Figure 6. Shows the soil classification index against different amounts of water being added to the soil with a range of 0 to $4000 \mathrm{~mL}$.

Apart from Stability, due to a few outliers in the dry conditions, the soil classification index remained fairly stable. Figure 7 shows the relationship for both \% gravel and \% sand versus the soil classification index when the soil moisture content ranges from $2 \%$ to less than $15 \%$ moisture content when using the ASD FieldSpec Spectroradiometer. Results show that we only had difficulty with one type of soil for predicting the \% gravel, but the trend did not fail even when the soil moisture was increased. The prediction for \% sand, however, worked for all the five soil types at varying moisture contents. No direct relation was found between the soil classification index and the $\%$ fine content, so instead knowing the remainder after excluding \% gravel and \% sand would be comprised of solely the \% fine content. Next, the relationships for when conditions are known about the moisture content: 2 to $<3 \%, 3$ to $<5 \%, 5$ to $<10 \%$, and 10 to $<15 \%$ moisture content are shown in Figure 8, with \% gravel in orange and \% sand in blue. The BaySpec hyperspectral camera was also used to find similar trends. The BaySpec camera was tested for values ranging from 2 to $5 \%$ moisture content, with one soil (Stability) having a single trial at $8 \%$, and the plots are displayed in Figure 9. 


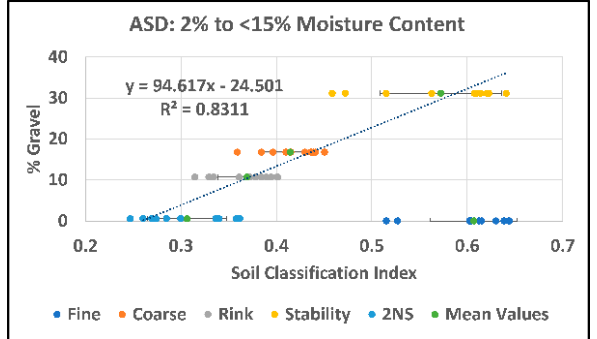

(a)

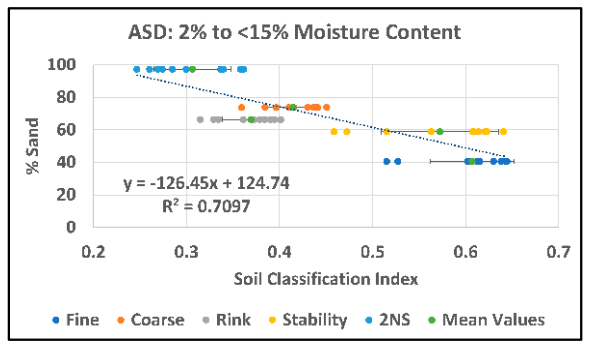

(b)

Figure 7. Trend lines for \% sand (a) and \% gravel content (b) among the five soils as recorded by the ASD FieldSpec spectroradiometer.

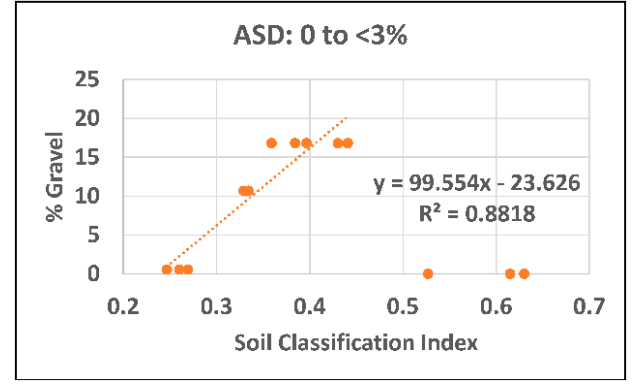

(a)

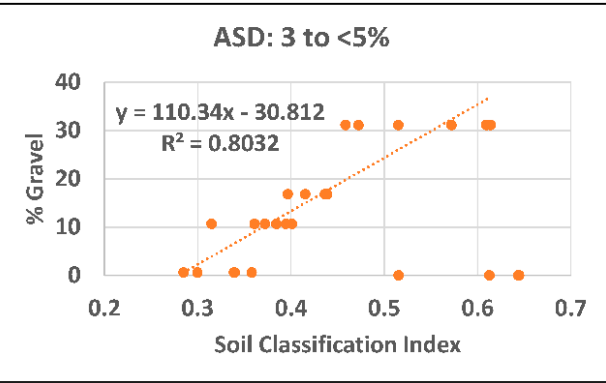

(c)

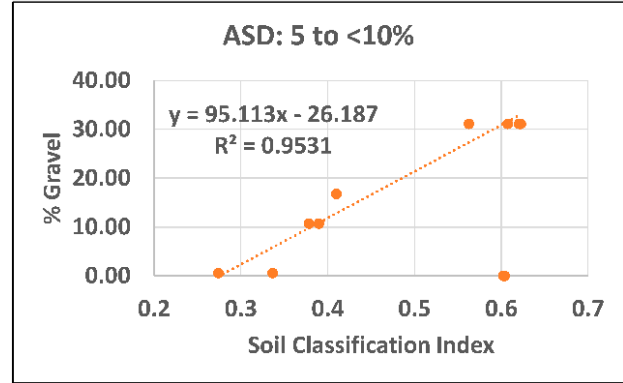

(e)

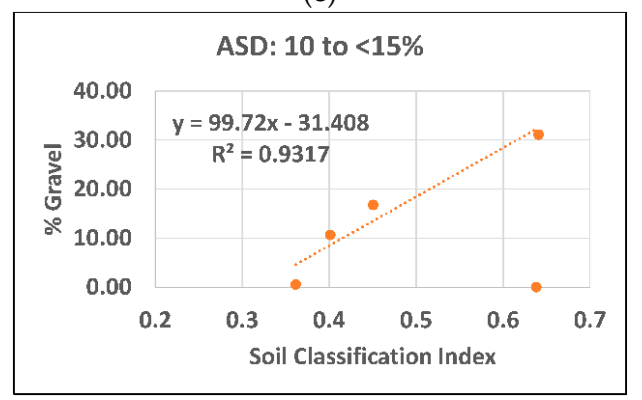

(g)

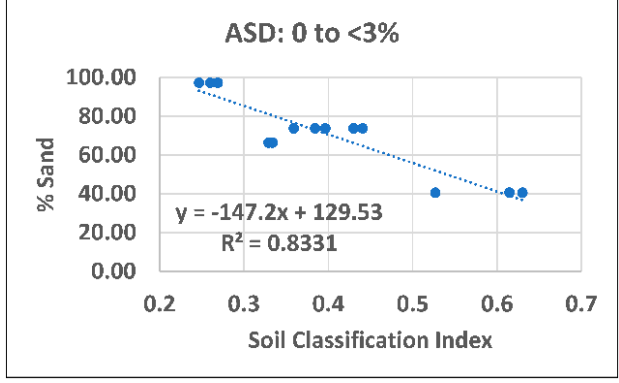

(b)

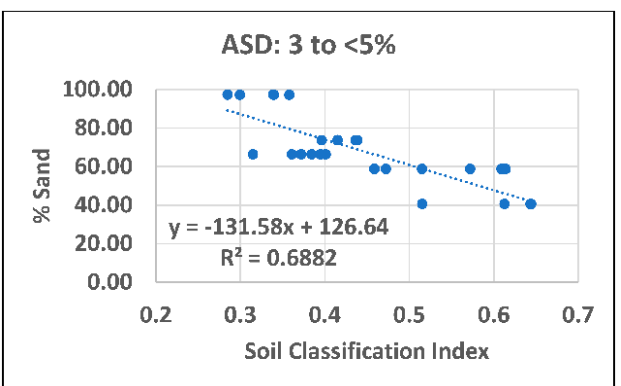

(d)

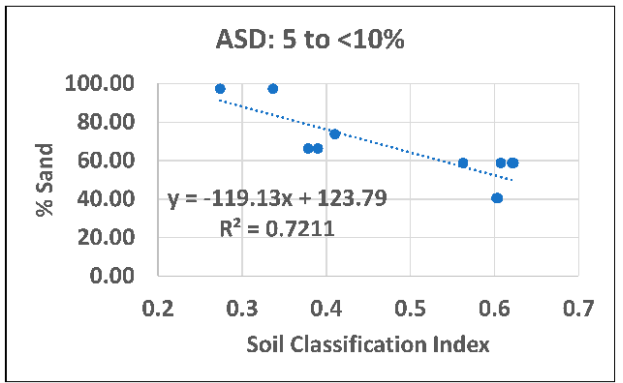

(f)

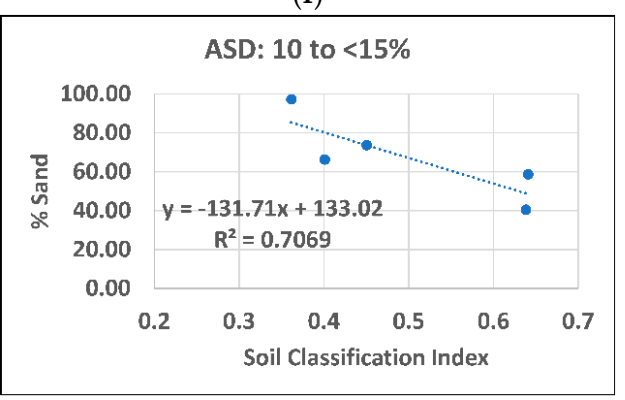

(h)

Figure 8. Each plot shows the soil classification index vs. \% Gravel (Orange- $(\mathbf{a}, \mathbf{c}, \mathbf{e}, \mathbf{g})$ ) or \% Sand (Blue- $(\mathbf{b}, \mathbf{d}, \mathbf{f}, \mathbf{h}))$ where moisture content starts at around $2 \%$ (top) and increases to about 15\% (bottom). 


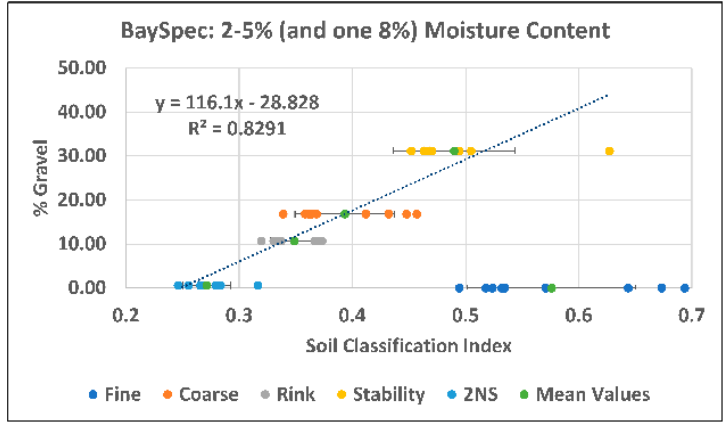

(a)

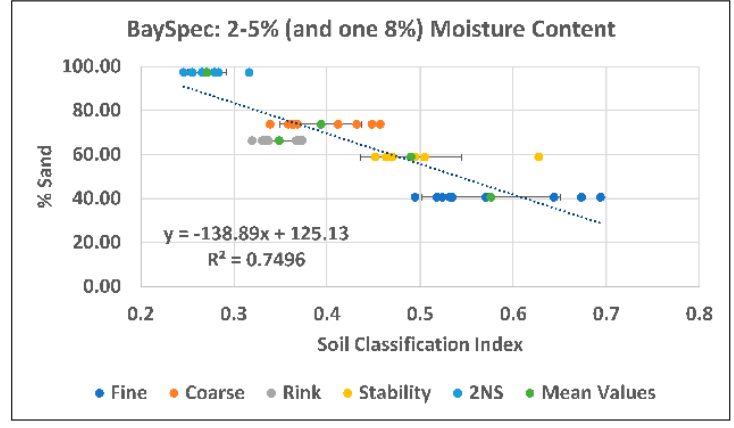

(b)

Figure 9. Trend lines for \% gravel (a) and \% sand (b) content among the five soils as recorded by the BaySpec hyperspectral camera.

When compared to the ASD, the trendlines for both \% gravel and \% sand versus the soil classification index, have similar trends as shown in Figure 10. The BaySpec and ASD trends slightly differ, while maintaining an accuracy of $86.2 \%$ (BaySpec) and $80 \%$ (ASD) for percent gravel estimation when under 5\% moisture content. The \% sand trends between the ASD and BaySpec devices are nearly parallel, while the prediction accuracy is either 73.3\% (ASD) or 77.9\% (BaySpec), also under $5 \%$ moisture content. Note that each trendline and its corresponding accuracy were made in accordance with each device's collected set of data, as seen in Figure 10.

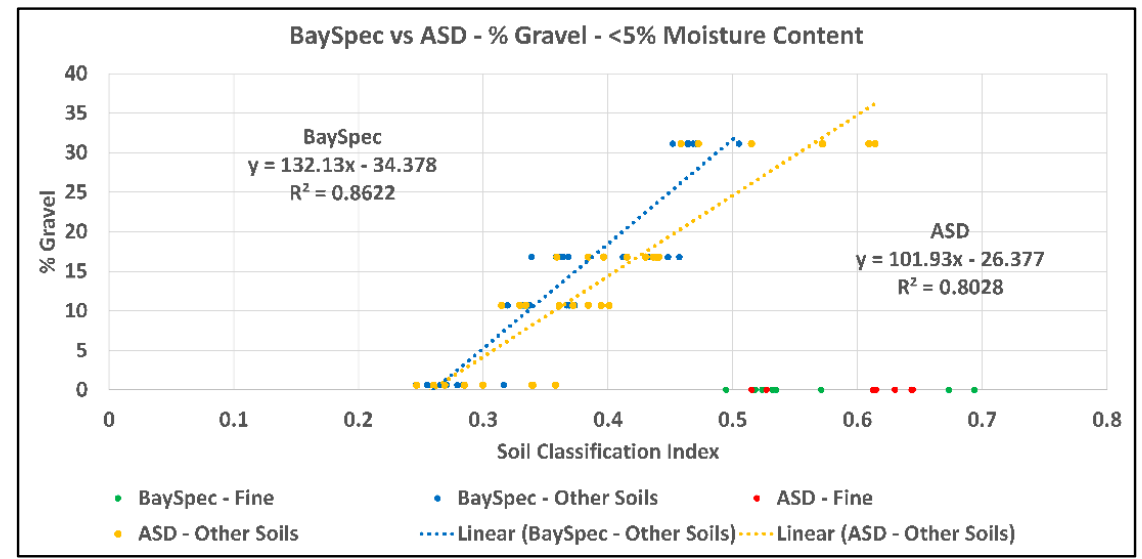

(a)

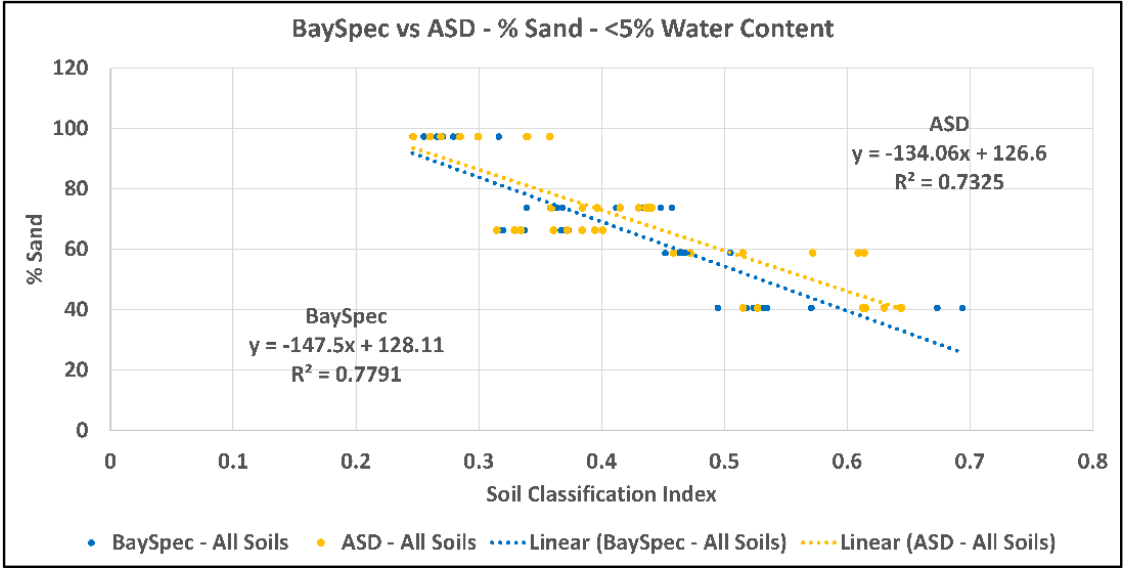

(b)

Figure 10. BaySpec and ASD plots for (a) \% Gravel vs. soil classification index and (b) \% Sand vs. soil classification index. 


\section{Discussion}

Trends for both \% gravel and \% sand versus the soil classification index have been shown in Figures 7-10. Similar to Lucas' work [33] who found a brightness index to distinguish between 22 different colored natural sands, a similar range of spectral values for our index to identify the gradation was used. Moreover, in agreement with Sousa [18] we found using hyperspectral imagery to identify our needed bands for the soil classification index very useful, this does turn the final model into a more "multispectral approach" yet still has great promise for soil mapping. Both the BaySpec and ASD Spectroradiometer detected these trends with R^2 values of 0.86 and 0.80 for \% gravel and 0.78 and 0.73 for \% sand. Other researchers [32] have been able to identify sand content using seven bands (in the range of 950-2400 nm) and getting an R^2 value of 0.85 within their laboratory study. This group had also found correlations to clay content in contrast to us identifying the \% gravel and \% fine content of the soil. Selige's work [35], however, was able to utilize HyMap imagery with partial least squares regression (PLSR) and multilinear regression (MLR) to get $R^{\wedge} 2$ values of 0.94 and 0.87 for sand content, respectively. That process used more predictors, nine factors for PLSR and four bands for MLR and the wavelengths used were in the range of $2200-2400 \mathrm{~nm}$. While work is being done in the wavelength range of 2000-2500 $\mathrm{nm}$ for clay and mineral identification research, this study is focused on simple gradation of the soil (\% gravel, \% sand, and \% fine content) as the BaySpec camera does not reach that wavelength range. Both these groups use wavelength ranges past the visible spectrum, use more bands thereby requiring a larger computational time than using our index, and would require a more expensive sensor to collect the bandwidths. Figure 6 shows that various amounts of water being added $0-4000 \mathrm{~mL}$ to the soil bins had little effect on the soil classification index. If the water content of the soil is known, then Figure 8 allows for better prediction accuracy in all but the 3 to $<5 \%$ water content for sand, and 0 to $<3 \%$ and 5 to $<10 \%$ water content for gravel. In other cases, the better prediction model comes from the $2 \%$ to $<15 \%$ water content model in Figure 7 .

Furthermore, for Figure 6, with the soil classification index remaining constant throughout adding varying milliliters of water to the soil, we assumed that 5-10 min was long enough for the water to soak into the soil. This may have led to skewing the moisture content: high water content in the top layer and drier in lower depths of the soils. This may be especially true within the Fine pit, with the highest fine particle content among the soil types making it the least permeable and potentially influencing its reflectance values. The moisture content probes, however, do an average over the entire soil depth, and the water had clearly soaked in beneath the visible surface of the soil.

Another potential reason for the fine soil not working for the soil classification index estimating $\%$ gravel in both devices could be due to the gravel content being zero, rather than having at least some gravel present as with the other four soils. Once the values of \% gravel and \% sand are known, the remaining makeup of the soil will consist of fine particles. Thus, giving one the entire particle size composition of the soil under examination. Specifics for the five soils tested are listed in Table 2. All the testing was done using pure soil samples and no organics present, which could skew the results when tested in the field. If prior knowledge of the site about whether or not organics are present would also allow for further classification to the soil type at hand to help get a better classification of the study site. A relation for remotely sensed data and the $\mathrm{Cc}$ and $\mathrm{Cu}$ could also be created to allow for a full USCS classification [36] of the soil down to specific soil type.

Table 2. Actual, Predicted, and Difference values for the $\%$ gravel, $\%$ sand, $\%$ fine for each of the five soils.

\begin{tabular}{cccc}
\hline $\begin{array}{c}\text { Soils } \\
\text { (Actual/Predicted/Difference) }\end{array}$ & $\begin{array}{c}\text { \% Gravel } \\
\text { (Act./Pred./Diff.) }\end{array}$ & $\begin{array}{c}\text { \% Sand } \\
\text { (Act./Pred./Diff.) }\end{array}$ & $\begin{array}{c}\text { \% Fine } \\
\text { (Act./Pred./Diff.) }\end{array}$ \\
\hline Fine & $0.0 / 42.8 /+42.8$ & $40.6 / 41.2 /+0.6$ & $59.4 / 16.0 /-43.4$ \\
Coarse & $16.8 / 17.3 /+0.5$ & $73.7 / 71.0 /-2.7$ & $9.5 / 11.7 /+2.2$ \\
Rink & $10.7 / 11.0 /+0.3$ & $66.4 / 78.4 /+12.0$ & $23.0 / 10.6 /-12.4$ \\
Stability & $31.1 / 30.8 /-0.3$ & $58.8 / 55.3 /-3.5$ & $10.0 / 13.9 /+3.9$ \\
2NS & $0.6 / 0.2 /-0.4$ & $97.3 / 91.0 /-6.3$ & $2.1 / 8.8 /+6.7$ \\
\hline
\end{tabular}




\section{Conclusions}

In conclusion, the present approach for soil gradation using sieve analysis of in situ soil samples can be costly or difficult to obtain. We have shown that using both a high resolution and a more cost-efficient hyperspectral sensor, one can pick up specific gradation details about each of the five different soils used in this study.

With the improvement of cameras and cost to develop hyperspectral and multispectral sensors reducing, these devices are going to become a much more readily available tool. These improvements in sensors have allowed us to create a soil classification index using values from the visible region of the reflectance spectrum. Utilizing the soil classification index, it is possible to remotely characterize the percent gravel, sand, and the remaining being fine soil. This method only requires the reflectance values at 550,600, and $650 \mathrm{~nm}$ within a visible/near infrared hyperspectral or multispectral image, given the sensor collects these particular bands. This soil classification index represented approximately the top $10-15 \mathrm{~cm}$ of the soil and remained relatively constant for each soil with increasing the moisture content. Knowing the approximate or actual moisture content of the soil helps improve the accuracy of the model.

Keeping in mind the limitations, being that of different sensor resolutions and what bands the hyperspectral sensors can pick up may not precisely be 550, 600, and $650 \mathrm{~nm}$ wavelengths. Different platforms and the presence of organics in the soil may also have different results than that which this study has found. Different minerals will also have an influence on the soil classification index, such minerals like Fe-Oxide minerals where goethite and hematite both have an absorption band around $500 \mathrm{~nm}$ [30]. In future work, we hope to expand this method into testing many different soil types outside the five used in this study. We also hope to investigate variations of the predictions of percent gravel and sand, based on organics being present in the field. Finally, we also would like to take this study to the UAV platform in the field and see how this study holds up outside of a constrained environment at differing spatial resolutions, potentially allowing for another index to identify the $\mathrm{Cu}$ and Cc of the soil to classify using the USCS system.

Author Contributions: J.E. and T.O. conceived and designed the experiments; J.E. and T.O. performed the experiments; J.E, T.O., and P.J. analyzed the data; J.E. and T.O. wrote the original draft preparation; J.E, T.O., P.J., and R.A. contributed to writing - review and editing. All authors have read and agreed to the published version of the manuscript.

Funding: This research was funded by the University of Michigan's Automotive Research Center (ARC), the U.S. Army Combat Capabilities Development Command Ground Vehicle Systems Center (CCDC-GVSC, formerly TARDEC), and Michigan Technological University (MTU).

Acknowledgments: We would like to thank the Keweenaw Research Center (KRC) for providing the logistics for data collection.

Conflicts of Interest: The authors declare no conflict of interest.

Disclaimer: Approved for public release; distribution unlimited. OPSEC\# 3737.

\section{References}

1. Cola, S.; Simonini, P. Mechanical behavior of silty soils of the Venice lagoon as a function of their grading characteristics. Can. Geotech. J. 2002, 39, 879-893. [CrossRef]

2. Kuenza, K.; Towhata, I.; Orense, R.P.; Wassan, T.H. Undrained torsional shear tests on gravelly soils. Landslides 2004, 1, 185-194. [CrossRef]

3. Simoni, A.; Houlsby, G.T. The Direct Shear Strength and Dilatancy of Sand-gravel Mixtures. Geotech. Geol. Eng. 2006, 24, 523-549. [CrossRef]

4. McCullough, D.M.; Jayakumar, D.P.; Dasch, D.J.; Gorsich, D.D. Developing the Next Generation NATO Reference Mobility Model. In Proceedings of the 2016 Ground Vehicle Systems Engineering and Technology Symposium, Novi, MI, USA, 2-4 August 2016.

5. Bouali, E.; Oommen, T.; Escobar-Wolf, R. Interferometric Stacking toward Geohazard Identification and Geotechnical Asset Monitoring. J. Infrastruct. Syst. 2016, 22. [CrossRef] 
6. Bouali, E.; Oommen, T.; Escobar-Wolf, R. Mapping of slow landslides on the Palos Verdes Peninsula using the California landslide inventory and persistent scatterer interferometry. Landslides 2018, 15, 439-452. [CrossRef]

7. Escobar-Wolf, R.; Oommen, T.; Brooks, C.N.; Dobson, R.J.; Ahlborn, T.M. Unmanned Aerial Vehicle (UAV)-Based Assessment of Concrete Bridge Deck Delamination Using Thermal and Visible Camera Sensors: A Preliminary Analysis. Res. Nondestruct. Eval. 2018, 29, 183-198. [CrossRef]

8. Minasny, B.; McBratney, A.B. Digital soil mapping: A brief history and some lessons. Geoderma 2016, 264, 301-311. [CrossRef]

9. Oommen, T.; Bouali, E.H.; Escobar-Wolf, R. New Paradigm in Geotechnical Performance Monitoring Using Remote Sensing. In Geotechnical Design and Practice; Springer: Singapore, 2019; pp. 195-201. [CrossRef]

10. Stark, N.; McNinch, J.; Wadman, H.; Graber, H.C.; Albatal, A.; Mallas, P.A. Friction angles at sandy beaches from remote imagery. Géotech. Lett. 2017, 7, 292-297. [CrossRef]

11. Rühlmann, M.; Büchele, D.; Ostermann, M.; Bald, I.; Schmid, T. Challenges in the quantification of nutrients in soils using laser-induced breakdown spectroscopy-A case study with calcium. Spectrochim. Acta Part B At. Spectrosc. 2018, 146, 115-121. [CrossRef]

12. Hong, H.; Churchman, G.J.; Yin, K.; Li, R.; Li, Z. Randomly interstratified illite-vermiculite from weathering of illite in red earth sediments in Xuancheng, southeastern China. Geoderma 2014, 214, 42-49. [CrossRef]

13. Yin, K.; Hong, H.; Churchman, G.J.; Li, Z.; Fang, Q. Mixed-layer illite-vermiculite as a paleoclimatic indicator in the Pleistocene red soil sediments in Jiujiang, southern China. Palaeogeogr. Palaeoclimatol. Palaeoecol. 2018, 510, 140-151. [CrossRef]

14. Środoń, J.; Drits, V.A.; McCarty, D.K.; Hsieh, J.C.; Eberl, D.D. Quantitative X-ray diffraction analysis of clay-bearing rocks from random preparations. Clays Clay Miner. 2001, 49, 514-528. [CrossRef]

15. Rossel, R.A.V.; McGlynn, R.N.; McBratney, A.B. Determining the composition of mineral-organic mixes using UV-vis-NIR diffuse reflectance spectroscopy. Geoderma 2006, 137, 70-82. [CrossRef]

16. Lamine, S.; Petropoulos, G.P.; Brewer, P.A.; Bachari, N.E.; Srivastava, P.K.; Manevski, K.; Kalaitzidis, C.; Macklin, M.G. Heavy Metal Soil Contamination Detection Using Combined Geochemistry and Field Spectroradiometry in the United Kingdom. Sensors 2019, 19, 762. [CrossRef]

17. Shaw, G.A.; Burke, H.-h.K. Spectral Imaging for Remote Sensing. Linc. Lab. J. 2003, 14, 3-28.

18. Sousa, D.; Small, C. Multisensor Analysis of Spectral Dimensionality and Soil Diversity in the Great Central Valley of California. Sensors 2018, 18, 583. [CrossRef]

19. Sahoo, B.C.; Oommen, T.; Misra, D.; Newby, G. Using the one-dimensional S-transform as a discrimination tool in classification of hyperspectral images. Can. J. Remote Sens. 2007, 33, 551-560. [CrossRef]

20. Vohland, M.; Ludwig, M.; Thiele-Bruhn, S.; Ludwig, B. Quantification of Soil Properties with Hyperspectral Data: Selecting Spectral Variables with Different Methods to Improve Accuracies and Analyze Prediction Mechanisms. Remote Sens. 2017, 9, 1103. [CrossRef]

21. Bowers, S.A.; Hanks, R.J. Reflectance of radiant energy from soils. Soil Sci. 1965, 100, 130-138. [CrossRef]

22. Sinha, A.K. Spectral reflectance characteristics of soils and its correlation with soil properties and surface conditions. J. Indian Soc. Remote Sens. 1986, 14, 1-9. [CrossRef]

23. Coleman, T.L.; Agbu, P.A.; Montgomery, O.L. Spectral Differentiation of Surface Soils and Soil Properties: Is It Possible from Space Platforms? Soil Sci. 1993, 155, 283-293. [CrossRef]

24. Orlov, D.; Sukhanova, N.; Rozanova, M. Spectral reflectance of soils and their components. Mosc. State Univ. Mosc. Russ. 2001, 200, 175.

25. Fox, G.A.; Sabbagh, G.J. Estimation of Soil Organic Matter from Red and Near-Infrared Remotely Sensed Data Using a Soil Line Euclidean Distance Technique. Soil Sci. Soc. Am. J. 2002, 66, 1922-1929. [CrossRef]

26. Barnes, E.M.; Sudduth, K.A.; Hummel, J.W.; Lesch, S.M.; Corwin, D.L.; Yang, C.; Daughtry, C.S.; Bausch, W.C. Remote-and ground-based sensor techniques to map soil properties. Photogramm. Eng. Remote Sens. 2003, 69, 619-630. [CrossRef]

27. Metternicht, G.; Zinck, A. Remote Sensing of Soil Salinization: Impact on Land Management, 1st ed.; CRC Press Inc.: Baton Rouge, LA, USA, 2008. [CrossRef]

28. Bellinaso, H.; Demattê, J.A.M.; Romeiro, S.A. Soil spectral library and its use in soil classification. Revista Brasileira de Ciência do Solo 2010, 34, 861-870. [CrossRef]

29. Prudnikova, E.; Savin, I. Effect of Open Soil Surface Patterns on Soil Detectability Based on Optical Remote Sensing Data. Proceedings 2018, 2, 357. [CrossRef] 
30. Fang, Q.; Hong, H.; Zhao, L.; Kukolich, S.; Yin, K.; Wang, C. Visible and Near-Infrared Reflectance Spectroscopy for Investigating Soil Mineralogy: A Review. J. Spectrosc. 2018, 2018, 3168974. [CrossRef]

31. Viscarra Rossel, R.A.; Cattle, S.R.; Ortega, A.; Fouad, Y. In situ measurements of soil colour, mineral composition and clay content by vis-NIR spectroscopy. Geoderma 2009, 150, 253-266. [CrossRef]

32. José, A.M.D.; Suzana, R.A.; Peterson, R.F. Variation of Routine Soil Analysis When Compared with Hyperspectral Narrow Band Sensing Method. Remote Sens. 2010, 2, 1998-2016. [CrossRef]

33. Ouillon, S.; Lucas, Y.; Gaggelli, J. Hyperspectral Detection of Sand. Presented at the Seventh International Conference on Remote Sensing for Marine and Coastal Evironments, Miami, FL, USA, 20-22 May 2002. Available online: http://www.legos.obs-mip.fr/members/ouillon/publications/Ouillon_et_al_Proc2002.pdf? lang=en (accessed on 8 October 2020).

34. Melgani, F.; Bruzzone, L. Classification of hyperspectral remote sensing images with support vector machines. IEEE Trans. Geosci. Remote Sens. 2004, 42, 1778-1790. [CrossRef]

35. Selige, T.; Böhner, J.; Schmidhalter, U. High resolution topsoil mapping using hyperspectral image and field data in multivariate regression modeling procedures. Geoderma 2006, 136, 235-244. [CrossRef]

36. ASTM D2487-17e1. Standard Practice for Classification of Soils for Engineering Purposes (Unified Soil Classification System); ASTM International: West Conshohocken, PA, USA, 2017. [CrossRef]

37. BaySpec, Inc. OCITM-F Ultra-Compact Hyperspectral Imager User Manual, 1.2 ed.; BaySpec, Inc.: San Jose, CA, USA, 2018; p. 66.

38. Zwissler, B.; Oommen, T.; Vitton, S.; Seagren, E.A. Thermal Remote Sensing For Moisture Content Monitoring of Mine Tailings: Laboratory Study. Environ. Eng. Geosci. 2017, 23, 299-312. [CrossRef]

39. Analytical Spectral Devices, Inc. (ASD). FieldSpec ${ }^{\circledR} 3$ User Manual. 2010. Available online: http:// www.geo-informatie.nl/courses/grs60312/material2017/manuals/600540-JFieldSpec3UserManual.pdf (accessed on 8 October 2020).

40. Campbell Scientific, Inc. CR1000X: Measurment and Control Datalogger. In Product Manual. 2018. Available online: https://s.campbellsci.com/documents/us/manuals/cr1000x-product-manual.pdf (accessed on 8 October 2020).

41. Campbell Scientific, Inc. CS615-Water Content Reflectometer. 1996. Available online: https://www. campbellsci.com/cs615-1 (accessed on 8 October 2020).

(C) 2020 by the authors. Licensee MDPI, Basel, Switzerland. This article is an open access article distributed under the terms and conditions of the Creative Commons Attribution (CC BY) license (http://creativecommons.org/licenses/by/4.0/). 